\title{
Sulfonylurea Induced Severe Hypoglycemia in a Diabetic with Renal Failure- A Case Report
}

\author{
Abdul H. Zaid*, Sunil Sapru, Jennifer Costello, Chirag Boradia \\ Saint Barnabas Medical Center, Livingston, USA \\ Email: *azaid@barnabashealth.org, Ssapru@barnabashealth.org, Jcostello@barnabashealth.org, \\ drboradia@gmail.com
}

Received 12 August 2015; accepted 14 November 2015; published 17 November 2015

Copyright (C) 2015 by authors and Scientific Research Publishing Inc.

This work is licensed under the Creative Commons Attribution International License (CC BY). http://creativecommons.org/licenses/by/4.0/

cC) (i) Open Access

\section{Abstract}

Introduction: Persistent hypoglycemia in the setting of acute renal insufficiency while on sulfonylureas is potentially a life-threatening complication. A case of severe hypoglycemia in a diabetic with acute on chronic renal insufficiency while on glimepiride is described here. Case Report: A seventy-six years old man presented to our emergency department with gradually progressive generalized weakness, dyspnea on exertion and lightheadedness. His medical history included congestive heart failure, hypertension and chronic kidney disease from non-insulin dependent diabetes. He reported good compliance with his medications which included glimepiride, 2 mg daily. Patient's spouse reported a blood sugar reading of $22 \mathrm{mg} / \mathrm{dL}$ at home which prompted the emergency department visit. On presentation, the patient was tachycardic, tachypneic and diaphoretic. Initial glucose meter reading was found to be $36 \mathrm{mg} / \mathrm{dL}$ and a blood glucose level on the metabolic panel was $49 \mathrm{mg} / \mathrm{dL}$. Patient serum creatinine was $2.5 \mathrm{mg} / \mathrm{dL}$, increased from a baseline of $1.8 \mathrm{mg} / \mathrm{dL}$. While in the emergency room, the patient received $50 \%$ dextrose intravenously eventually requiring an intravenous infusion of $10 \%$ dextrose. Despite this treatment, the patient remained persistently hypoglycemic with blood sugars less than $80 \mathrm{mg} / \mathrm{dL}$. A decision was made at this point to administer 50 micrograms of octreotide subcutaneously. Two hours later, the patient's blood sugar started to improve and the intravenous $10 \%$ dextrose was discontinued. Eight hours later, the patient received another dose of 50 micrograms of octreotide and remained consistently euglycemic. Upon discharge, he was asked to discontinue glimepiride. Conclusion: Severe refractory hypoglycemia is a serious complication of sulfonylurea therapy in diabetics with renal insufficiency. Prompt recognition and initiation of octreotide are effective in reversing hypoglycemia in these instances rapidly and safely.

\footnotetext{
${ }^{*}$ Corresponding author.
}

How to cite this paper: Zaid, A.H., Sapru, S., Costello, J. and Boradia, C. (2015) Sulfonylurea Induced Severe Hypoglycemia in a Diabetic with Renal Failure-A Case Report. Journal of Biosciences and Medicines, 3, 68-70. 


\section{Keywords}

\section{Persistent Hypoglycemia, Chronic Renal Insufficiency}

\section{Introduction}

Hypoglycemia is a recognized complication of sulfonylurea overdose [1]. Acute or chronic renal insufficiency can potentiate these effects and may result in life threatening hypoglycemia even with therapeutic doses [1]. The mechanism of sulfonylurea toxicity is secondary to the exertion of the sulfonylurea pharmacological properties. Sulfonylureas reduce blood glucose concentrations by stimulating the release of insulin from pancreatic betacells. Preformed insulin is released from secretory granules within the beta-cells as a result of the sulfonylureainduced inhibition of ATP-dependent potassium channels and the resulting membrane depolarization and calcium influx. Severe hypoglycemia can be observed when blood glucose concentrations fall and supply of glucose to the brain becomes diminished. The risk of hypoglycemia has been reported to be highest with longacting sulfonylureas such as chlorpropamide, glyburide, and long-acting glipizide [2]. Early symptoms of hypoglycemia from sulfonylureas are characterized by weakness, hunger, diaphoresis, pallor, palpitations, sinus tachycardia, headache, irritability, and tremor. If hypoglycemia remains untreated, neuroglycopenia may develop resulting in impaired concentration and judgment, confusion, blurred vision, drowsiness, and amnesia. Further progression can result in seizures and/or coma, and possibly death [3]. The onset of hypoglycemia typically occurs within 8 to 12 hours of ingestion [3] [4]; however, it may also be delayed for up to 24 hours with the use of long-acting agents. In addition, the duration of hypoglycemia may also be prolonged due to the presence of active metabolites of sulfonylureas in the setting of renal insufficiency.

Conventional therapy of hypoglycemia with intravenous dextrose infusions may only temporarily correct blood sugar levels as sulfonylurea and active metabolite levels may remain high for a prolonged period of time resulting in persistent hypoglycemia. Although octreotide use has been advocated as a first line therapy, indications and dosing are not firmly established [5] [6]. It has also been identified that the use of octreotide may reduce the incidence of recurrent hypoglycemia that is seen with dextrose-alone therapy [7]. Administration via intravenous bolus and intravenous infusion has been described in the literature, although subcutaneous administration is the preferred route for octreotide administration [8].

Persistent hypoglycemia in the setting of acute renal insufficiency while on sulfonylureas is potentially a lifethreatening complication. Our case report discusses a patient with severe hypoglycemia resulting from acute on chronic renal insufficiency while maintained on low dose glimepiride (Amaryl ${ }^{\mathbb{B}}$ ) monotherapy (2 mg daily) and highlights the response to treatment with octreotide after failed attempts to correct the patient's hypoglycemia with dextrose.

\section{Case Report}

A seventy-six years old man presented to our emergency department with gradually progressive generalized weakness, dyspnea on exertion and lightheadedness. His medical history included congestive heart failure, hypertension and chronic kidney disease from non-insulin dependent diabetes. He reported good compliance with his medications which included glimepiride, two mg taken daily. Patient's spouse reported a blood sugar reading of $22 \mathrm{mg} / \mathrm{dL}$ at home which prompted the emergency department visit. On presentation, the patient was tachycardic, tachypneic and diaphoretic. Initial glucose meter reading was found to be $36 \mathrm{mg} / \mathrm{dL}$ and a blood glucose level on the metabolic panel was $49 \mathrm{mg} / \mathrm{dL}$. Patient serum creatinine was $2.5 \mathrm{mg} / \mathrm{dL}$, increased from a baseline of $1.8 \mathrm{mg} / \mathrm{dL}$. While in the emergency room, the patient received six, $25 \mathrm{ml}$ vials of $50 \%$ dextrose intravenously and then required an intravenous infusion of $10 \%$ dextrose running at a rate of $100 \mathrm{ml} / \mathrm{hour}$. Despite the above treatment, he remained persistently hypoglycemic with blood sugars ranging from 60 to 80 $\mathrm{mg} / \mathrm{dL}$. A decision was made at this point to administer 50 micrograms of octreotide subcutaneously. Two hours later, the patient's blood sugar started to improve to $100 \mathrm{mg} / \mathrm{dL}$ and the intravenous $10 \%$ dextrose was discontinued. Eight hours later, the patient received another dose of 50 micrograms of octreotide. By now, he remained consistently euglycemic with blood sugars ranging from $140-180 \mathrm{mg} / \mathrm{dL}$. Upon discharge, he was asked to discontinue glimepiride and was started on repaglinide for glycemic control. 


\section{Discussion}

Severe refractory hypoglycemia is a serious complication of sulfonylurea therapy in diabetics with renal insufficiency [1]. Our case report highlights that severe hypoglycemia can occur with even low doses of glimepiride (2 mg daily) and concomitant renal insufficiency. Prompt recognition and initiation of octreotide are effective in reversing hypoglycemia rapidly and safely [5] [9]. Limited available data suggest that octreotide should be used as first line therapy in treatment of such cases [5]. However, formalized recommendations regarding its use and dosing are lacking. The ease of administration, quick onset and favorable side effect profile make octreotide an attractive agent in reversing severe hypoglycemia from glimepiride use.

\section{Conflict of Interest}

The authors do have any financial or other conflicts.

\section{References}

[1] Cryer, P.E., Davis, S.N. and Shamoon, H. (2003) Hypoglycemia in Diabetes. Diabetes Care, 26, 1902-1912. http://dx.doi.org/10.2337/diacare.26.6.1902

[2] Stahl, M. and Berger, W. (1999) Higher Incidence of Severe Hypoglycaemia Leading to Hospital Admission in Type 2 Diabetic Patients Treated with Long-Acting versus Short Acting Sulphonylureas. Diabetic Medicine, 16, 586-590. http://dx.doi.org/10.1046/j.1464-5491.1999.00110.x

[3] Spiller, H.A. (1998) Management of Antidiabetic Medications in Overdose. Drug Safety, 19, 411-424. http://dx.doi.org/10.2165/00002018-199819050-00007

[4] Boyle, P.J., Justice, K., Krentz, A.J., Nagy, R.J. and Schade, D.S. (1993) Octreotide Reverses Hyperinsulinemia and Prevents Hypoglycemia Induced by Sulfonylurea Overdoses. Journal of Clinical Endocrinology \& Metabolism, 76, 752-756.

[5] Glatstein, M., Scolnik, D. and Bentur, Y. (2012) Octreotide for the Treatment of Sulfonylurea Poisoning. Clinical Toxicology, 50, 795-804. http://dx.doi.org/10.3109/15563650.2012.734626

[6] Barkin, J.A., Block, H.M. and Mendez, P.E. (2013) Octreotide: A Novel Therapy for Refractory Sulfonylurea-Induced Hypoglycemia. Pancreas, 42, 722-723. http://dx.doi.org/10.1097/MPA.0b013e3182769c26

[7] Fasano, C.J., O’Malley, G., Dominici, P., Aguilera, E. and Latta, D.R. (2008) Comparison of Octreotide and Standard Therapy versus Standard Therapy Alone for the Treatment of Sulfonylurea-Induced Hypoglycemia. Annals of Emergency Medicine, 51, 400-406. http://dx.doi.org/10.1016/j.annemergmed.2007.06.493

[8] Sandostatin ${ }^{\circledR}$ [Package Insert] (2012) Novartis Pharmaceuticals Corporation, East Hanover.

[9] Vallurupalli, S. (2010) Safety of Subcutaneous Octreotide in Patients with Sulfonylurea-Induced Hypoglycemia and Congestive Heart Failure. Annals of Pharmacotherapy, 44, 387-390. http://dx.doi.org/10.1345/aph.1M433 